\title{
Meckel's Diverticulum Diagnosed in a Child with Suspected Small Bowel Crohn's Disease
}

\author{
Hyun Sik Kang, Jeong Sub Lee*, Chang Rim Hyun ${ }^{\dagger}$, In-Ho Jung ${ }^{\ddagger}$, and Ki Soo Kang \\ Departments of Pediatrics, ${ }^{*}$ Radiology, ${ }^{\dagger}$ Pathology, and ${ }^{\dagger}$ Surgery, Jeju National University School of Medicine, Jeju, \\ Korea
}

\begin{abstract}
We report a rare case of Meckel's diverticulum in a boy who initially presented with chronic iron deficiency anemia (IDA) without any history of gastrointestinal (GI) bleeding at 8 years-old. Isolated small bowel Crohn's disease was suspected based on findings of small bowel ulcers on capsule endoscopy. At four years from initial presentation, he developed massive Gl bleeding. Abdominal computed tomographic angiography and small bowel series revealed findings suggestive of Meckel's diverticulum. Meckel's diverticulum should be suspected in children with unexplained chronic IDA even in the absence of prominent GI bleeding and negative findings on repetitive Meckel's scans. Moreover, Meckel's diverticulum should be included in the differential diagnosis of isolated small bowel Crohn's disease when the disease is limited to a short segment of the distal small bowel, as ulcers and inflammation may result as a consequence of acid secreted from adjacent heterotopic gastric mucosa constituting the Meckel's diverticulum.
\end{abstract}

Key Words: Meckel diverticulum, Iron deficiency anemia, Crohn disease

\section{INTRODUCTION}

Meckel's diverticulum is one of the most common congenital malformation of the gastrointestinal (GI) tract that results from an incomplete involution of the omphalomesenteric tract or vitelline duct [1]. Most patients with Meckel's diverticulum remain asymptomatic lifelong, but children with the disease may develop symptoms of massive GI bleeding and rare complications, including intestinal obstruction, intussusception, hernia, inflammation, and perfo- ration [1-4]. In rare cases, chronic iron-deficiency anemia (IDA) has also been reported as the first manifestation of Meckel's diverticulum [5,6].

Crohn's disease (CD) is a chronic progressive inflammatory bowel disease (IBD) that is capable of affecting any part of the GI tract [7]. CD typically manifestates with symptoms of abdominal pain, diarrhea, and weight loss, however, in children with CD approximately one fourth of children will present with growth failure, anemia, perianal diseiase, or other extrintestinal manifestations as the only pre-

Received : October 29, 2018, Revised : November 27, 2018, Accepted : December 14, 2018

Corresponding author: Ki Soo Kang, Division of Gastroenterology, Hepatology and Nutrition, Department of Pediatrics, Jeju National University School of Medicine, 15 Aran 13-gil, Jeju 63241, Korea. Tel: +82-64-754-8146, Fax: +82-64-717-1131, E-mail: kskang@jejunu.ac.kr

Copyright (c) 2019 by The Korean Society of Pediatric Gastroenterology, Hepatology and Nutrition

This is an open-access article distributed under the terms of the Creative Commons Attribution Non-Commercial License (http://creativecommons.org/licenses/by-nc/4.0/) which permits unrestricted non-commercial use, distribution, and reproduction in any medium, provided the original work is properly cited. 
dominant initial feature [8]. Considering its natural course of progressive behavior, early and accurate diagnosis as well as effective treatment is crucial especially in children with CD $[9,10]$.

Meanwhile, anemia is the most common extraintestinal manifestation of IBD [11]. IDA and anemia of chronic disease (ACD) are the two types of anemia in patients with IBD, and may present separately or simultaneously [12]. In IBD patients, GI blood loss, malabsorption, and decreased oral intake following poor appetite are factors that contribute to IDA, while increased hepcidin activity resulting in decreased red blood cell production and decreased iron absorption via the small intestine are known as the mechanisms involved with ACD in IBD [13].

The authors report a rare case of an 8-year-old boy initially presenting with severe chronic IDA leading to the suspicion of isolated small bowel CD based on capsule endoscopic findings, who was later diagnosed with Meckel's diverticulum on abdominal computed tomographic angiography and small bowel series performed after an event of massive GI bleeding.

\section{CASE REPORT}

An 8-year-old boy presented to the emergency department of our institution with pallor and general weakness that had progressed for 3 months. He and his parent denied gross GI bleeding such as hematochezia and melena. He was not a vegetarian, and his appetite and dietary habit were normal. He had a chronically ill-looking appearance and his conjunctiva were anemic. His body weight was $33.5 \mathrm{~kg}$ (75th-90th percentile); height, $136 \mathrm{~cm}$ (90th-95th percentile); and body mass index, $18.1 \mathrm{~kg} / \mathrm{m}^{2}$ (50th-75th percentile). Blood pressure was $111 / 52$ mmHg; pulse, 110 beats per minute; respiratory rate, 24 breaths per minute, and temperature, $37.4^{\circ} \mathrm{C}$. His mental status was alert. His heart beat was regular without murmur, and breath sound was clear. His abdomen was soft without any organomegaly. No abnormal findings were noted on neurologic examamination. A laboratory workup revealed the following values: hemoglobin, $3.5 \mathrm{~g} / \mathrm{dL}$; hematocrit, $14 \%$; white blood cell count, 4,800/ $\mathrm{L}$; platelet count,

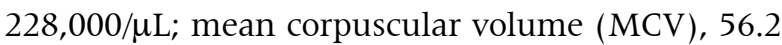
$\mathrm{fL}$; mean corpuscular hemoglobin $(\mathrm{MCH}), 14.1 \mathrm{pg}$; red cell distribution width, 19.6\%; and corrected reticulocyte, $0.4 \%$. Prothrombin time and activated partial prothrombin time were 14.1 and 29 seconds, respectively. Serum iron level was $7 \mu \mathrm{g} / \mathrm{dL}$; total iron binding capacity, $383 \mu \mathrm{g} / \mathrm{dL}$; and serum ferritin level, $1.4 \mathrm{ng} / \mathrm{mL}$. Total protein level was $6.5 \mathrm{~g} / \mathrm{dL}$, albumin level, $4.5 \mathrm{~g} / \mathrm{dL}$; and C-reactive protein (CRP) level, $0.01 \mathrm{mg} / \mathrm{dL}$. Stool occult blood was negative. Other laboratory tests were all normal.

To rule out the possibility of obscure GI bleeding, several studies were performed. The findings of Meckel's scan were negative (Fig. 1A). Abdominal computed tomography revealed focal wall thickening and enhancement in the ileocecal valve and terminal ileum (Fig. 2A). Gastroduodenoscopy and colonoscopy revealed no abnormal mucosal findings, and histology results from random biopsies were also unremarkable, including negative results for Helicobacter pylori colonization in the stomach. Capsule endoscopy revealed localized multiple aphthous ulcers and diffuse erythematous mucosa in the distal ileum (Fig. 3).

Considering the initial impression of isolated small bowel Crohn's disease, oral mesalazine and iron supplements were started. During follow-up, he was well without any symptoms and signs of illness, and his hemoglobin level fluctuated from 10.3 to $11.2 \mathrm{~g} / \mathrm{dL}$, and serum ferritin level also fluctuated from 4.71 to $18.24 \mathrm{ng} / \mathrm{mL}$. He arbitrarily stopped taking mesalazine at 2 years from the initial diagnosis, but continued taking iron supplements.

At 4 years from the initial diagnosis, he presented to the emergency department with melena and syncope that had occurred the day before his vist. His hemoglobin level was $7.7 \mathrm{~g} / \mathrm{dL}$, hematocrit was $23.4 \%$, MCV was $69.6 \mathrm{fL}$, and MCH was $21.1 \mathrm{pg}$. Erythrocyte sedimentation rate was $6 \mathrm{~mm} /$ hour and CRP level was $0.04 \mathrm{mg} / \mathrm{dL}$. Fecal calprotectin level was $>2,000$ $\mathrm{mg} / \mathrm{kg}$. Other laboratory findings were all normal. Results of Meckel's scan were again negative (Fig. 

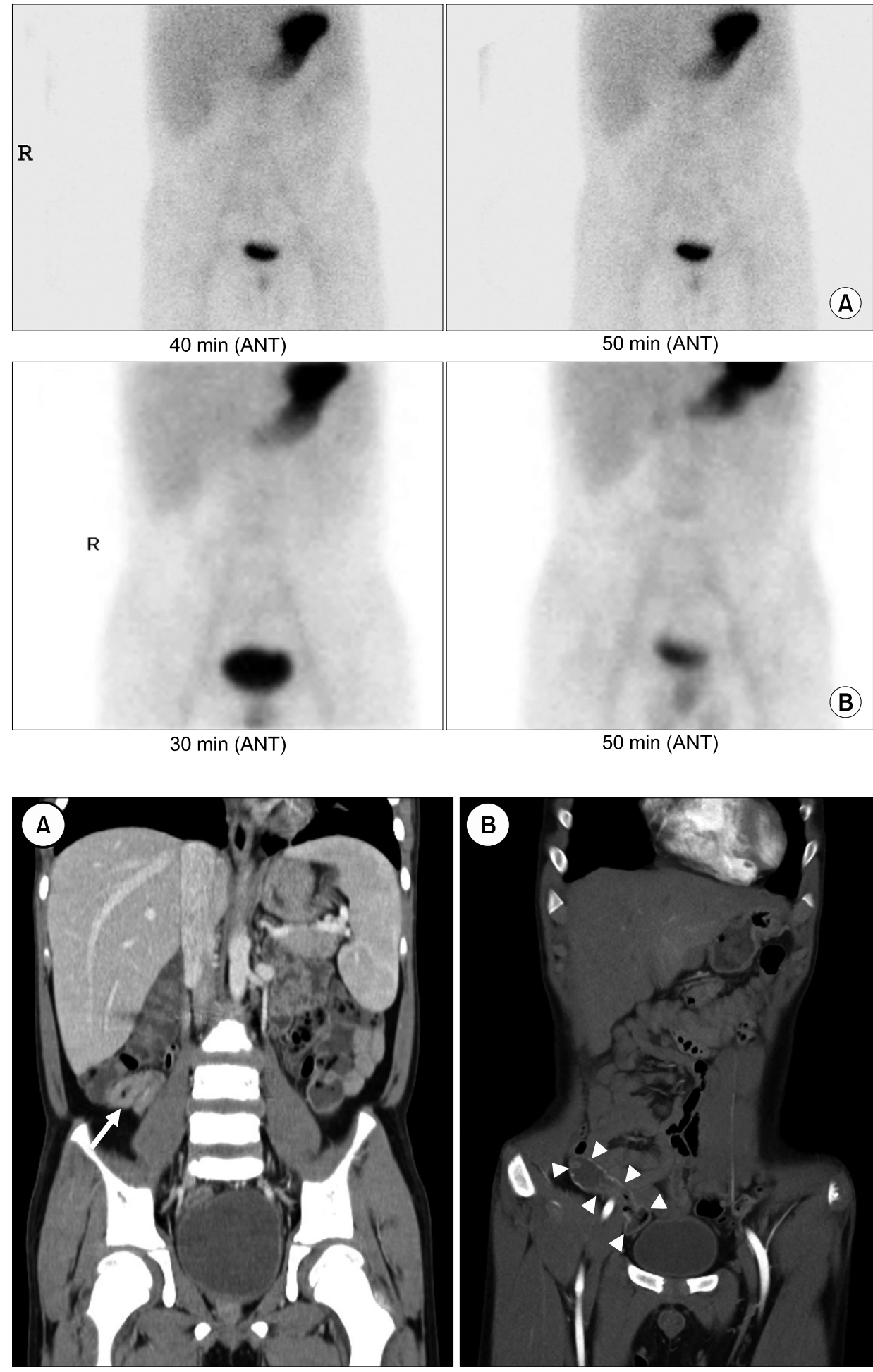

Fig. 2. Abdominal computed tomography image at initial presentation (A) and 4 years later (B). Initial findings reveal wall thickening of the terminal ileum (arrow) but no other remarkable findings $(\mathrm{A})$, while a prominent enhancing tubular structure (arrowheads) connected to the distal ileum with a blind end (B) were noted 4 years later.
1B). Gastroduodenoscopy, colonoscopy, and capsule endoscopy also revealed no identifiable cause of bleeding as well as no abnormal mucosal findings in the GI tract. However, abdominal computed tomographic angiography revealed a prominent enhancing tubular structure connected to the distal ileum 


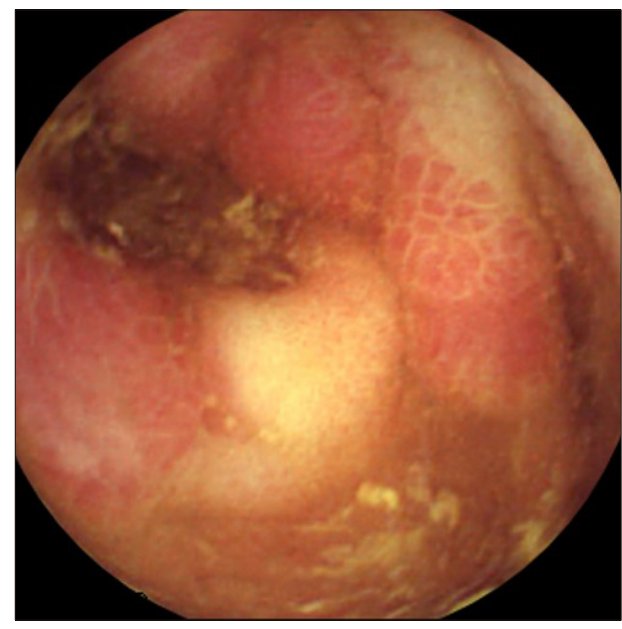

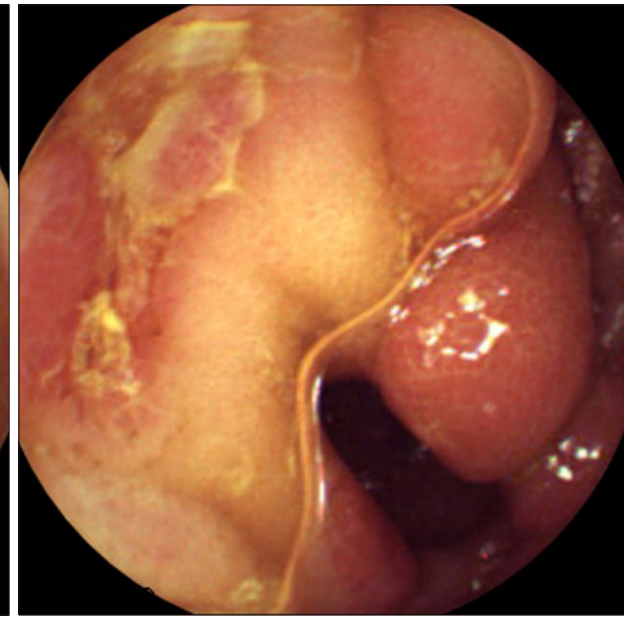

Fig. 3. Capsule endoscopy image at initial presnetation demonstrating diffuse erythematous mucosa and multiple aphthous ulcers in the distal ileum.

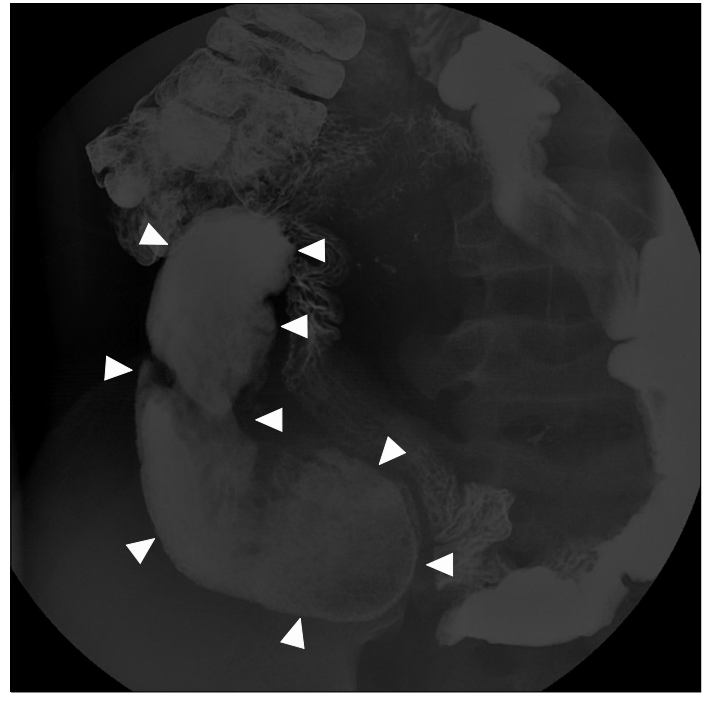

Fig. 4. Small bowel barium study performed 4 years later showing a contrast-filling structure $(9.7 \mathrm{~cm})$ outside and inferior to the terminal ileum, suspicious of Meckel's diverticulum (arrowheads).

(Fig. 2B). Small bowel series also revealed a contrast filling structure suspected with a duplication cyst or Meckel's diverticulum in the distal ileum (Fig. 4). Laparoscopic resection of the lesion was performed (Fig. 5A), and histologic evaluation revealed pyloric glands within the diverticulum, thereby confirming the diagnosis of Meckel's diverticulum (Fig. 5B). The patient was discharged on the fifth postoperative day. At follow-up 5 months later, he revealed a se- rum hemoglobin level of $14.3 \mathrm{~g} / \mathrm{dL}$, hematocrit level of $41.6 \%$, MCV of $80.2 \mathrm{fL}, \mathrm{MCH}$ of $27.6 \mathrm{pg}$, and serum ferritin level of $48.49 \mathrm{ng} / \mathrm{mL}$.

\section{DISCUSSION}

Unlike the typical presentation of symptomatic Meckel's diverticulum that manifests with massive GI bleeding, chronic IDA was the only symptom the patient presented with in this case. Internal bleeding was initially suspected, considering the relatively low hemogoblin levels $(3.5 \mathrm{~g} / \mathrm{dL})$. However, the patient's history and physical examination were unremarkable. Considering the possibility of unnoticed GI bleeding, despite the fact that stool occult blood was negative, endoscopic and radiologic exams in order to rule out GI bleeding as well as iron malabsorption were conducted. However, all exams revealed negative results except localized apthous ulcers and and diffuse erythematous mucosa in the distal ileum, leading to the working diagnosis of isolated small bowel CD. Due to its nonspecific symptoms and anatomical location, the diagnosis of isolated small bowel CD is difficult [14]. Isolated small bowel $\mathrm{CD}$ has been reported to consist $2.9 \%$ of all phenotypes in children [15]. However, with the development of capsule endoscopy, the diagnosis rate of small bowel $\mathrm{CD}$ has increased with findings varing from erythema, mucosal edema, ulceration, loss of 

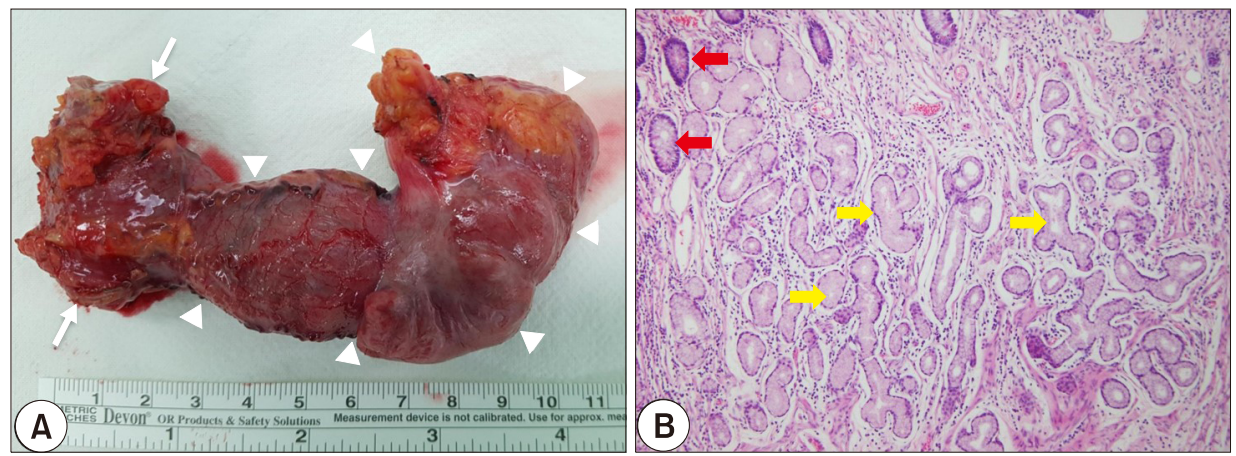

Fig. 5. Diverticulectomy specimen (A) and histology (B). The specimen shows a segment of the ileum with a Meckel's diverticulum (arrowheads) of approximately 9-cm length (arrows) (A). Light microscopy image shows a low-power view with a mixture of gastric (yellow arrows) and intestinal epithelia (red arrows) within the Meckel's diverticulum $(\mathrm{H} \& \mathrm{E}, \times 100)(\mathrm{B})$.

villi, mucosal fissures, and stenosis on capsule endoscopy $[16,17]$. Meanwhile, additional studies to confirm the diagnosis of small bowel $\mathrm{CD}$ in this case including small bowel enterography was not conducted considering the short disease involvement, and double-balloon enteroscopy with biopsy was also not considered because of the young age of the patient.

Several studies have reported the association between Meckel's diverticulum and CD [18-20]. According to a retrospective study that had reviewed 294 patients with CD that had undergone right hemicolectomy reported that a Meckel's diverticulum was found in $5.8 \%$ of these patients, which is 2 to 3 times higher than the general population [19]. Moreover, no heterotopic mucosa was found in the coincidentally detected diverticula in the resected small bowel of CD patients, while at least $50 \%$ of diverticula in the general population contain a heterotopic mucosa [19]. Meanwhile, a recent study that reviewed 48 consecutive surgical resections performed for Meckel's diverticulum concluded that ileitis affecting a short segment of mucosa and submucosa in the small intestine near a Meckel's diverticulum was relatively common, and was not necessarily related to CD [21]. In these points of view, the initial ulcers and erythema observed on capsule endoscopy in this case may have been a result a secondary change in the acid secretion from the heterotopic gastric mucosa in Meckel's diverticulum rather than due to small bowel CD itself. Moreover, this postulation is strengthened by the fact that the initial lesions had disappeared on capsule endoscopy conducted 4 years later by just taking only oral mesalazine for 2 years. It is known that small bowel CD is generally known to be highly resistant to current treatments, leading to complications such as stricture and perforation [14]. Furthermore, mesalazine is only modestly effective with a trend towards benefit over placebo in mild to moderate CD [22].

Meckel's scan has a sensitivity of $80 \%$ to $90 \%$, specificity of $95 \%$, and accuracy of $90 \%$ [23-25]. Although the oral $\mathrm{H}_{2}$ blocker was administered for 48 hours before Meckel's scans in the present case, no abnormal finding was detected. Likewise despite the repeated Meckel's scans, the diagnosis of Meckel's diverticulum may be difficult in some cases [26]. A recent case report has also shown that Meckel's scan can be negative even when gastric mucosa is present within the diverticulum [27]. Similar to our case, the patient in this case presented with IDA, revealed negative findings on Meckel's scan, and Meckel's diverticulum was detected on computed tomography and small-bowel follow through [27]. Thus, Meckel's diverticulum should be suspected in children with unexplained chronic IDA even in the absence of prominent GI bleeding and negative findings on repetitive Meckel's scans, and further evaluation including enterography of the small bowel should be considered in these patients. 
In conclusion, we report a rare case of an 8-yearold boy initially presenting with severe chronic IDA leading to the suspicion of isolated small bowel Crohn's disease, who was later diagnosed with Meckel's diverticulum after an event of massive GI bleeding. Meckel's diverticulum should be suspected in children with unexplained chronic IDA even in the absence of prominent GI bleeding and negative findings on repetitive Meckel's scans. Moreover, Meckel's diverticulum should be included in the differential diagnosis of isolated small bowel CD when the disease is limited to a short segment of the distal small bowel, as ulcers and inflammation may result as a consequence of acid secreted from adjacent heterotopic gastric mucosa constituting the Meckel's diverticulum.

\section{REFERENCES}

1. Yahchouchy EK, Marano AF, Etienne JC, Fingerhut AL. Meckel's diverticulum. J Am Coll Surg 2001;192: 658-62.

2. Park JJ, Wolff BG, Tollefson MK, Walsh EE, Larson DR. Meckel diverticulum: the Mayo Clinic experience with 1476 patients (1950-2002). Ann Surg 2005;241: 529-33.

3. Huang CC, Lai MW, Hwang FM, Yeh YC, Chen SY, Kong MS, et al. Diverse presentations in pediatric Meckel's diverticulum: a review of 100 cases. Pediatr Neonatol 2014;55:369-75.

4. Bani-Hani KE, Shatnawi NJ. Meckel's diverticulum: comparison of incidental and symptomatic cases. World J Surg 2004;28:917-20.

5. Al-Onaizi I, Al-Awadi F, Al-Dawood AL. Iron deficiency anaemia: an unusual complication of Meckel's diverticulum. Med Princ Pract 2002;11:214-7.

6. Goodwin B, Smith M. Meckel's diverticulum as a cause of persistent anaemia. ANZ J Surg 2018;88:112-3.

7. Baumgart DC, Sandborn WJ. Inflammatory bowel disease: clinical aspects and established and evolving therapies. Lancet 2007;369:1641-57.

8. Rosen MJ, Dhawan A, Saeed SA. Inflammatory bowel disease in children and adolescents. JAMA Pediatr 2015;169:1053-60.

9. Kang B, Choi SY, Kim HS, Kim K, Lee YM, Choe YH. Mucosal healing in paediatric patients with moderate-to-severe luminal Crohn's disease under combined immunosuppression: escalation versus early treatment.
J Crohns Colitis 2016;10:1279-86.

10. Kang B, Choe YH. Early biologic treatment in pediatric Crohn's disease: catching the therapeutic window of opportunity in early disease by treat-to-target. Pediatr Gastroenterol Hepatol Nutr 2018;21:1-11.

11. Murawska N, Fabisiak A, Fichna J. Anemia of Chronic disease and iron deficiency anemia in inflammatory bowel diseases: pathophysiology, diagnosis, and treatment. Inflamm Bowel Dis 2016;22:1198-208.

12. Gasche C, Lomer MC, Cavill I, Weiss G. Iron, anaemia, and inflammatory bowel diseases. Gut 2004;53:1190-7.

13. Aljomah G, Baker SS, Schmidt K, Alkhouri R, Kozielski $\mathrm{R}$, Zhu L, et al. Anemia in pediatric inflammatory bowel disease. J Pediatr Gastroenterol Nutr 2018;67:351-5.

14. Hall B, Holleran G, McNamara D. Small bowel Crohn's disease: an emerging disease phenotype? Dig Dis 2015; 33:42-51.

15. de Bie CI, Paerregaard A, Kolacek S, Ruemmele FM, Koletzko S, Fell JM, et al. Disease phenotype at diagnosis in pediatric Crohn's disease: 5-year analyses of the EUROKIDS Registry. Inflamm Bowel Dis 2013;19: 378-85.

16. Yen HH, Chang CW, Chou JW, Wei SC. Balloon-assisted enteroscopy and capsule endoscopy in suspected small bowel Crohn's disease. Clin Endosc 2017;50: 417-23.

17. Enns RA, Hookey L, Armstrong D, Bernstein CN, Heitman SJ, Teshima C, et al. Clinical practice guidelines for the use of video capsule endoscopy. Gastroenterology 2017;152:497-514.

18. Glick SN, Maglinte DD, Herlinger H. Association of Meckel's diverticulum and Crohn's disease. Gastrointest Radiol 1988;13:67-71.

19. Andreyev HJ, Owen RA, Thompson I, Forbes A. Association between Meckel's diverticulum and Crohn's disease: a retrospective review. Gut 1994;35:788-90.

20. Freeman HJ. Meckel's diverticulum in Crohn's disease. Can J Gastroenterol 2001;15:308-11.

21. Hamilton CM, Arnason T. Ileitis associated with Meckel's diverticulum. Histopathology 2015;67:783-91.

22. Lim WC, Wang Y, MacDonald JK, Hanauer S. Aminosalicylates for induction of remission or response in Crohn's disease. Cochrane Database Syst Rev 2016; 7:CD008870.

23. Kong MS, Chen CY, Tzen KY, Huang MJ, Wang KL, Lin JN. Technetium-99m pertechnetate scan for ectopic gastric mucosa in children with gastrointestinal bleeding. J Formos Med Assoc 1993;92:717-20.

24. Sinha CK, Pallewatte A, Easty M, De Coppi P, Pierro A, Misra D, et al. Meckel's scan in children: a review of 183 cases referred to two paediatric surgery specialist 
centres over 18 years. Pediatr Surg Int 2013;29:511-7.

25. Suh M, Lee HY, Jung K, Kim SE. Diagnostic accuracy of Meckel scan with initial hemoglobin level to detect symptomatic Meckel diverticulum. Eur J Pediatr Surg 2015;25:449-53.

26. Sagar J, Kumar V, Shah DK. Meckel's diverticulum: a systematic review. J R Soc Med 2006;99:501-5.

27. Qualia CM, Drugas GT, Jones LT. Meckel's diverticulum on small-bowel follow-through series and computerized tomography scan in a 7-year-old boy with anemia. Clin Gastroenterol Hepatol 2007;5:e42-3. 